\title{
Infections of the Skin among Children in Ho Teaching Hospital of the Volta Region, Ghana
}

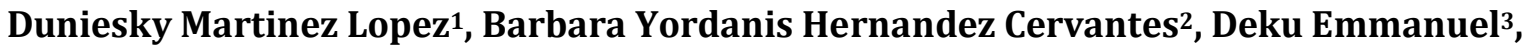 \\ Percival D. Agordoh4*, Fernando Miguel Almaguer², Radisnay Guzman Lambert ${ }^{2}$, \\ Virtue F. De-Gaulle5, Lennox Mac-Ankrah6, Francis A. Akum7, Verner N. Orish6
}

${ }^{1}$ Department of Internal Medicine, School of Medicine, University of Health and Allied Sciences, Ho, Volta Region, Ghana

${ }^{2}$ Department of Surgery, School of Medicine, University of Health and Allied Sciences, Ho, Volta Region, Ghana

${ }^{3}$ School of Medicine, University of Health and Allied Sciences, Ho, Volta Region, Ghana

${ }^{4}$ Department of Nutrition and Dietetics, School of Allied Health Sciences, University of Health and Allied Sciences, Ho, Ghana

${ }^{5}$ MARCAD Project, School of Medicine School of Medicine, University of Health and Allied Sciences, Ho, Volta Region, Ghana

${ }^{6}$ Department of Microbiology and Immunology, School of Medicine, University of Health and Allied Sciences, Ho, Volta Region, Ghana

${ }^{7}$ Department of Public Health, Bawku Presbyterian Hospital, Bawku, Upper East Region, Ghana

Email: *pagordoh@uhas.edu.gh

How to cite this paper: Lopez, D.M., Cervantes, B.Y.H., Emmanuel, D., Agordoh, P.D., Almaguer, F.M., Lambert, R.G., De-Gaulle, V.F., Mac-Ankrah, L., Akum, F.A. and Orish, V.N. (2020) Infections of the Skin among Children in Ho Teaching Hospital of the Volta Region, Ghana. Open Access Library Journal, 7: e6192.

https://doi.org/10.4236/oalib.1106192

Received: February 26, 2020

Accepted: March 24, 2020

Published: March 27, 2020

Copyright $\odot 2020$ by author(s) and Open Access Library Inc.

This work is licensed under the Creative Commons Attribution International License (CC BY 4.0). http://creativecommons.org/licenses/by/4.0/

\section{Open Access}

\begin{abstract}
Skin infections are common disorders responsible for hospital attendance in the pediatric practice. Unfortunately, the epidemiology of these infections in tertiary facilities is both unstudied and underreported. Therefore, the burden of skin infections among children in Ghana remains indistinct. This hospital-based study sought to evaluate skin infections among children attending the Ho Teaching Hospital (HTH). In this retrospective study, the electronic medical records of children aged 0 to 14 years $(12,170)$ who attended the HTH's pediatric unit outpatient clinic between January 1, 2015 and December 31, 2016 were reviewed. All $(1,877)$ identified dermatological case records from the database were retrieved. They were then double-checked to further affirm demographic information (age and sex) and diagnosis of skin infection with the medical folders to clarify unclear observations. Pearson chi square was used to evaluate the association between the different age group of the children and the types of skin infection as well as comorbidities. Only 1, 887 (15.5\%) of all case records reported with a presenting dermatological complaint. Sixty-five percent (65\%) of these (1226 of 1887) were diagnosed with a form of skin infection. Sixty-nine percent (69\%) of children with skin infection were admitted into the ward for further management. Majority (441, $35.97 \%$ ) of skin infected children were between 1 - 4 yrs. Impetigo (393, $46.6 \%)$ and furunculosis $(410,48.6 \%)$ were the most prevalent skin infections compared to herpes $(3,6.5 \%)$ and warts $(4,8.7 \%)$. The parasitic skin infection
\end{abstract}


recorded in this study was scabies $(23,100 \%)$. Gender disparity existed, with female children aged 10 - 14 years significantly having more skin infection than males $(<0.001)$. The prevalence of skin infections was $65.3 \%$ of childhood dermatological cases in the HTH. Further studies are needed to evaluate the skin infections burden in other parts of Ghana.

\section{Subject Areas}

Infectious Diseases

\section{Keywords}

Skin Infections, Children, Prevalence, Hospital, Medical Records

\section{Introduction}

Skin infections constitute about $26 \%$ of all skin diseases in the global disease burden of 2013 [1]. Infections of the skin are common skin disorders in children responsible for majority of the outpatient visits in hospitals and clinics [2]. Children are prone to infections due to their underdeveloped immunity [3] and poor hygiene practices especially among children in low socioeconomic settings [4].

The four major types of pathogens responsible for most infectious diseases have all been implicated in the etiology of skin infections. Viral skin infections, the most common skin infections seen among children [5], represent the modal infection of all skin infections reported globally in 2013 [1]. Fungal skin infections are the second most common skin infections among children [6], followed by bacterial, with the least type being parasitic skin infection [1].

In Ghana studies have shown that skin infection is a problem especially among children [7] [8] [9]. Fungal and bacterial skin infections have been reported as the most prevalent skin infections among school children in Ghana [9]. Further studies are needed to evaluate the burden of skin infections among children in other parts of Ghana. Thus, this hospital-based study was designed to evaluate skin infections among children attending the Ho Teaching Hospital.

\section{Methodology}

\subsection{Study Area and Population}

This study took place in the Ho Teaching Hospital of the Volta region of Ghana. The region is one of the 16 regions of the country located at latitudes $50^{\circ} 45^{\prime \prime} \mathrm{N}$ and $80^{\circ} 45^{\prime \prime} \mathrm{N}$ in the south-eastern part of the country. It is bounded by Togo on the east and Lake Volta on the west. The study specifically took place at the outpatient department (OPD) of pediatric and child health unit of the Ho Teaching Hospital which provides both outpatient and inpatient services to an average of 7000 OPD attendance plus over 3000 admissions yearly. 


\subsection{Study Design}

This study was a retrospective study involving the retrieval and review of the medical records of all the children from the ages of $0-14$ years who attended OPD over a 2 years period from January 12015 to December 31, 2016. The sampling frame for this study was the hospital's patient electronic data base known as the Hospital Administrative Management Systems (HAMS). By hospital policy, details of all cases seen in the unit are logged into the HAMS by diagnosis and audited. Only records of confirmed diagnoses were included in this study. In cases where the HAMS provided inadequate information, the medical records were obtained to clarify issues and resolve indeterminate results.

\subsection{Ethical Consideration}

Formal permission was sought from the managing authorities of the hospital and the head of the pediatric unit of the hospital before the commencement of the study. Information obtained from patients' record was done under strict confidentiality and anonymity with numeric codes being assigned to names of all the cases reviewed.

\subsection{Data Analysis}

Statistical analysis was done using SPSS statistical software version 20. Frequency distribution was done for gender, age, types of skin infections and comorbidities. Pearson chi square was used to evaluate the association between the different age group of the children and the types of skin infection as well as comorbidities. Statistical significance for chi square was set at $p$-value $<0.05$. Records with missing or outlying data were excluded from analyses of the missing variables.

\section{Result}

A total of 12, 170 children were seen in the outpatient department of the pediatric unit of the Ho Teaching Hospital during the 2 years period under review (Figure 1). Of these, only 1887 reported with a dermatological complaint. A total of 1226 out of the 1887 children with dermatological complaints were diagnosed as one form of skin infection or the other. Sixty-nine of these children with skin infection were admitted into the ward for further management while 1157 were managed via the OPD.

Majority of the 1226 children with skin infection were between the ages of 1 4 years $(441,35.97 \%)$ (Table 1$)$. The age group with the least number of children with skin infections are the neonates, children less than 28 days old $(100,8.16 \%)$ (Table 1). There were almost an equal number of females $(614,50.08 \%)$ and males $(612,49.92 \%)$ who had skin infection in this study.

Figure 2 shows the type of skin infection among the children who visited the outpatient department of the pediatric and child health unit of the hospital. Impetigo $(393,46.6 \%)$ and furunculosis $(410,48.6 \%)$ were the most prevalent skin infections seen among the infected children. The least infections were herpes 


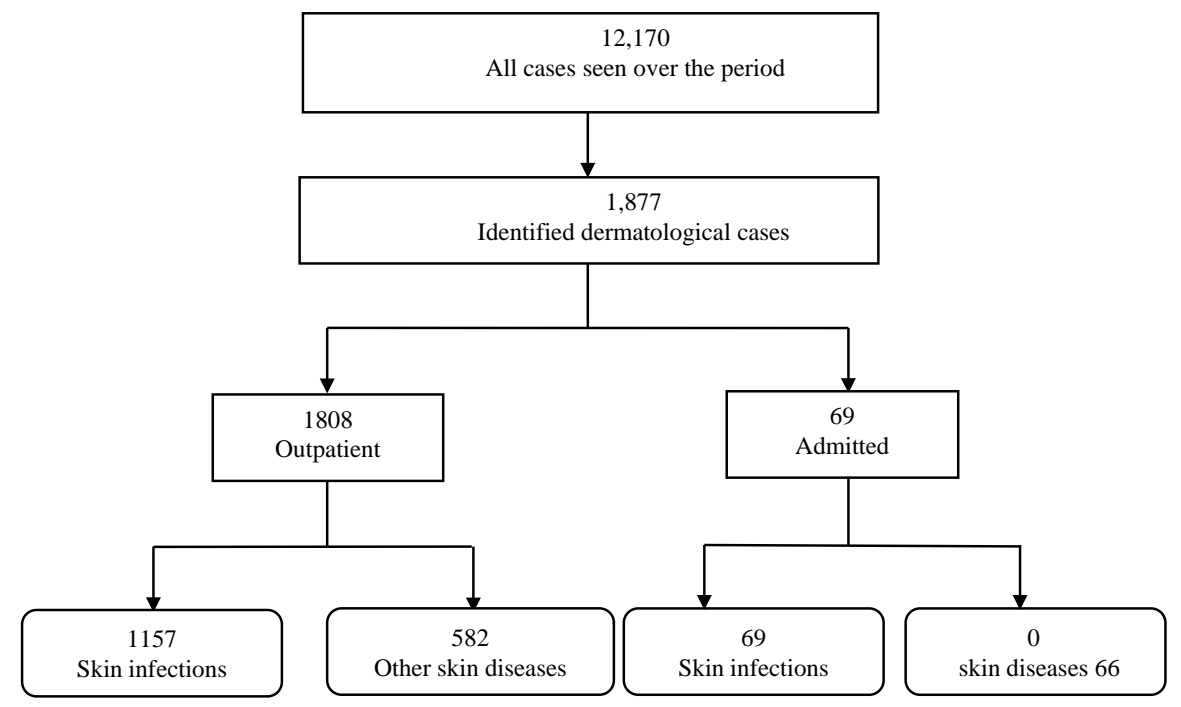

Figure 1. Flow chart of Pediatric cases over the 2-year period under study.

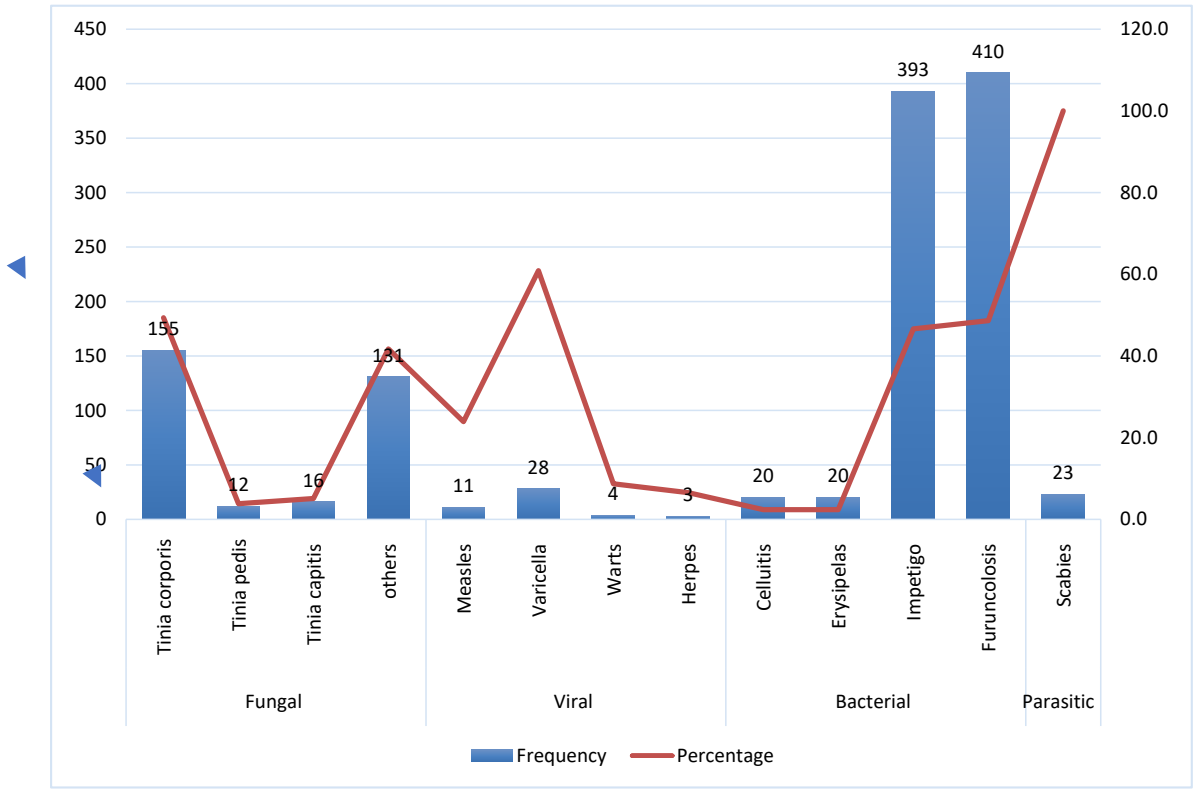

Figure 2. Types of skin infection.

and warts with only $3(6.5 \%)$ and $4(8.7 \%)$ children presenting with the viral skin infections. The only parasitic skin infection recorded in this study was scabies $(23,100 \%)$.

There was a gender disparity with the age group of 10 - 14 years significantly $(p<0.001)$ having more females $(106,50.72)$ with skin infection that males $(4$, $3.05 \%)$. A significant higher proportion of children between the ages of $1-12$ months had the most bacterial skin infection $(263,76.2 \%, p<0.001)$, fungal skin infection was seen more in older children between the ages of 5 and 9 years 12861.2; $p<0.001)$. Sepsis as a comorbidity was significantly higher in younger children 0 - 28 days $(14,35 \%)$ and $1-12$ months old $(8,44 \%, p<0.001)$ than in other age groups (Table 2). 
Table 1. General characteristics of children with infection of the skin.

\begin{tabular}{|c|c|c|}
\hline Characteristics & Frequency & $\%$ \\
\hline \multicolumn{3}{|l|}{ Age } \\
\hline 0 - 28 days & 100 & 8.16 \\
\hline $1-12$ months & 345 & 28.14 \\
\hline $1-4$ years & 441 & 35.97 \\
\hline $5-9$ years & 209 & 17.05 \\
\hline $10-14$ years & 131 & 10.69 \\
\hline \multicolumn{3}{|l|}{ Gender } \\
\hline Male & 612 & 49.92 \\
\hline Female & 614 & 50.08 \\
\hline \multicolumn{3}{|c|}{ Types of skin infections } \\
\hline Fungal & 314 & 25.61 \\
\hline Parasitic & 23 & 1.88 \\
\hline Viral & 46 & 3.75 \\
\hline Bacterial & 843 & 68.76 \\
\hline Comorbidity & 82 & 6.69 \\
\hline Diarrhea & 7 & 8.5 \\
\hline Sepsis & 28 & 34.15 \\
\hline Pneumonia & 11 & 13.41 \\
\hline Malaria & 21 & 25.61 \\
\hline HIV & 12 & 14.63 \\
\hline Neonatal jaundice & 11 & 13.41 \\
\hline
\end{tabular}

\section{Discussion}

In this study, dermatological conditions especially skin infections constituted a small proportion $(<20 \%)$ of all the recorded hospital visits at the outpatient department of the pediatrics unit of the Ho Teaching Hospital over the 2 years period under consideration, a finding that is similar to some other studies done on the African continent [10] [11] [12]. The relatively low prevalence of skin infections in this study might not be surprising as many skin diseases are managed at home by caregivers using various herbal remedies and off-the-counter medications. More so, studies have indicated that some caregivers of children with such cases often usually visit health centers rather than tertiary health institutions like the Ho Teaching Hospital [11] [13].

The result of this study further affirms the predominance of skin infections among dermatological cases, reported by several studies [10] [11] [12] [13]. This was probably due to the environmental and poor socioeconomic factors like poor sanitation and hygiene as well as inadequate water supply, which are usual risk factors for skin infections [13]. Bacterial skin infections especially furunculosis 
Table 2. General characteristics of children stratified by age.

\begin{tabular}{|c|c|c|c|c|c|c|}
\hline Characteristics & 0 - 28 days $[100]$ & $1-12$ months [345] & $<5$ years $[441]$ & 5 - 9 years [209] & $10-14$ years $[131]$ & $p$ Value \\
\hline \multicolumn{7}{|l|}{ Gender } \\
\hline Male & $63[63]$ & $185[53.62]$ & $251[56.92]$ & $103[49.28]$ & $4[3.05]$ & \multirow{2}{*}{$<0.001$} \\
\hline Female & $37[37]$ & $160[46.38]$ & $190[43.08]$ & $106[50.72]$ & 127 [96.95] & \\
\hline \multicolumn{7}{|l|}{ Infections } \\
\hline Bacteria & $96[96]$ & $263[76.2]$ & $299[67.8]$ & $64[30.6]$ & $121[92.4]$ & \\
\hline Viral & $2[2]$ & $14[4.1]$ & $19[4.3]$ & $17[8.2]$ & $1[0.8]$ & \\
\hline Fungal & $2[2]$ & $60[17.4]$ & $108[24.5]$ & $128[61.2]$ & $9[6.9]$ & \\
\hline Parasitic & $0[0]$ & $8[2.3]$ & $15[3.4]$ & $0[0]$ & $0[0]$ & \\
\hline Comorbidity & 40 & 18 & 17 & 11 & 6 & \multirow[t]{3}{*}{$<0.001$} \\
\hline Diarrhea & $0[0]$ & $1[5.6]$ & $3[17.6]$ & $2[18.8]$ & $1[16.7]$ & \\
\hline Sepsis & $14[35]$ & $8[44.4]$ & $2[11.8]$ & $3[16.7]$ & $1[16.7]$ & \\
\hline Pneumonia & $7[17.5]$ & $3[37.5]$ & $0[0]$ & $0[0]$ & $1[16.7]$ & \multirow{3}{*}{0.7} \\
\hline Malaria & $0[0]$ & $0[0]$ & $12[70.6]$ & $6[33.3]$ & $3[50.0]$ & \\
\hline HIV & $8[20]$ & $4[22.2]$ & $0[0]$ & $0[0]$ & $0[0]$ & \\
\hline Neonatal jaundice & $11[27.5]$ & $0[0]$ & $0[0]$ & $0[0]$ & $0[0]$ & \\
\hline
\end{tabular}

and impetigo were the most common infections in this study probably because they often present with the most worrisome symptoms like fever, pain and other manifestations of inflammation, invoking the desire of parents and guardians to seek help from health care providers [13]. This might probably explain the paucity of the prevalence of viral and parasitic infections in this study, whose symptoms are often less worrisome and are often alleviated with several herbal preparations available in tropical and developing countries [14].

A low prevalence of Measles, a viral disease with classical skin rash, was seen in this study. This finding is very much arguable as there was no outbreak of measles during the period under review. As a disease of public health concern, cases of measles are required to be promptly reported to the disease surveillance office which actively implements interventions to control the infections which includes national childhood immunization schedule. This finding may probably be related to a wrong diagnosis of measles rash which is not an uncommon occurrence in medical practice [15].

Neonates significantly had the highest proportion of bacterial skin infections compared to the other groups of children. The skin of infants especially neonates are said to be fragile and permeable to environmental assaults like pathogens especially bacteria compared to adults [16] [17]. Also, neonates significantly recorded more comorbidities in this study like sepsis, pneumonia, HIV and neonatal jaundice. Some of these comorbidities are probably complications of the predominant bacterial skin infections among this age group. Most bacterial skin infections like impetigo and furunculosis if improperly managed can result in 
sepsis and other sequalae [18]. Fungal skin infection or mycoses was the second most common infection in this study. It was seen more in older children, a finding that is corroborated by another study done in India [19]. Superficial mycoses was mainly seen in this study which is the common presentation of most hospital reported mycoses [20] [21] [22].

This retrospective study has some inherent limitations which is not uncommon to most retrospective studies. The fact that there are no available diagnostic protocols in arriving at the various diagnosis of skin infection in this study, gives room to scepticism regarding the accuracy of the diagnosis reached by the physicians. However, the facility is a tertiary center with high caliber and experienced physicians whose expertise will reduce the chance of wrong diagnosis to a minimum. There is other useful information like the socioeconomic status of the children that were not provided in this study. This information would have thrown more light on the risk factors. Despite these limitations, this study provided useful information on the types of skin infections in the tertiary hospital setting in the region.

\section{Conclusion}

This study recorded a high prevalence of skin infections among children who reported with skin diseases to the pediatric clinic during the study period. Bacterial infections constituted the majority of the infections in this study, with children under one (1) year of age proportionally having the highest of the infection and subsequent complications. Skin infections remain a public health concern that should be promptly diagnosed and adequately treated. This also includes employing appropriately targeted preventive measures.

\section{Conflicts of Interest}

The authors declare no conflicts of interest regarding the publication of this paper.

\section{References}

[1] Karimkhani, C., Dellavalle, R.P., Coffeng, L.E., Flohr, C., Hay, R.J., Langan, S.M., et al. (2017) Global Skin Disease Morbidity and Mortality an Update from the Global Burden of Disease Study 2013. JAMA Dermatology, 153, 406-412. https://doi.org/10.1001/jamadermatol.2016.5538

[2] Ogunbiyi, A.O., Owoaje, E. and Ndahi, A. (2012) Prevalence of Skin Disorders in School Children. The Internet Journal of Health, 13, 6-10. https://doi.org/10.1111/j.1525-1470.2005.22101.x

[3] Hooven, T.A. and Polin, R.A. (2014) Healthcare-Associated Infections in the Hospitalized Neonate: A Review. Early Human Development, 90, S4. https://doi.org/10.1016/S0378-3782(14)70002-7

[4] Wasnik, S., Pinto, V. and Joshi, S. (2018) Prevalence of Skin Infections and Regular Personal Hygiene Practices in Ashram School Students: A Cross-Sectional Study. National Journal of Community Medicine, 9, 274-277. 
[5] Sladden, M.J. and Johnston, G. (2004) Clinical Review Common Skin Infections in Children. British Medical Journal, 329, 95-99. http://www.ncbi.nlm.nih.gov/pmc/articles/PMC449820/pdf/bmj32900095.pdf https://doi.org/10.1136/bmj.329.7457.95

[6] Jain, A., Jain, S. and Rawat, S. (2010) Emerging Fungal Infections among Children: A Review on Its Clinical Manifestations, Diagnosis, and Prevention. Journal of Pharmacy and Bioallied Sciences, 2, 314-320. https://doi.org/10.4103/0975-7406.72131

[7] Kyeremateng, K.W. (2018) Assessment of Skin Infections among Long-Stayed Patients at the Accra Psychiatric Hospital in Ghana. Doctoral Dissertation, University of Ghana, Ghana.

[8] Ocansey, B.K., Pesewu, G.A., Codjoe, F.S., Osei-Djarbeng, S., Feglo, P.K. and Denning, D.W. (2019) Estimated Burden of Serious Fungal Infections in Ghana. Journal of Fungi, 5, 38. https://doi.org/10.3390/jof5020038

[9] Hogewoning, A., Bavinck, J.N.B., Willemze, R., Lavrijsen, A., Amoah, A., Boakye, D., et al. (2013) Skin Diseases among School Children in Ghana, Gabon, and Rwanda. International Journal of Dermatology, 52, 589-600. https://doi.org/10.1111/j.1365-4632.2012.05822.x

[10] Doe, P.T., Asiedu, A., Acheampong, J.W. and Rowland-Payne, C.M. (2001) Skin Diseases in Ghana and the UK. International Journal of Dermatology, 40, 323-326. https://doi.org/10.1046/j.1365-4362.2001.01229.x

[11] Maheé, A., N’Diaye, H.T. and Bobin, P. (1997) The Proportion of Medical Consultations Motivated by Skin Diseases in the Health Centers of Bamako (Republic of Mali). International Journal of Dermatology, 36, 185-186. https://doi.org/10.1046/j.1365-4362.1997.00140.x

[12] Rosenbaum, B.E., Klein, R., Hagan, P.G., Seadey, M., Quarcoo, N.L., Hoffmann, R., et al. (2017) Dermatology in Ghana: A Retrospective Review of Skin Disease at the Korle Bu Teaching Hospital Dermatology Clinic. The Pan African Medical Journal, 26, 125.

[13] World Health Organization (2005) Epidemiology and Management of Common Skin Diseases in Children in Developing Countries. No. WHO/FCH/CAH/05.12. World Health Organization.

[14] Tabassum, N. and Mariya, H. (2014) Plants Used to Treat Skin Diseases. Pharmacognosy Reviews, 15, 52-60. https://doi.org/10.4103/0973-7847.125531

[15] Kimura, H., Shirabe, K., Takeda, M., Kobayashi, M. and Cosby, S.L. (2019) The Association between Documentation of Koplik Spots and Laboratory Diagnosis of Measles and Other Rash Diseases in a National Measles Surveillance Programme in Japan. Frontiers in Microbiology, 10, 269. https://doi.org/10.3389/fmicb.2019.00269

[16] Stamatas, G.N., Nikolovski, J., Luedtke, M.A., Kollias, N. and Wiegand, B.C. (2010) Infant Skin Microstructure Assessed in Vivo Differs from Adult Skin in Organization and at the Cellular Level. Pediatric Dermatology, 27, 125-131. https://doi.org/10.1111/j.1525-1470.2009.00973.x

[17] Read, J. (2014) Cutaneous Manifestations of Neonatal Bacterial Infection. Australian Medical Student Journal, 5, 72-74.

[18] Hedrick, J. (2003) Acute Bacterial Skin Infections in Pediatric Medicine. Paediatric Drugs, 5, 35-46.

[19] Dogra, S. and Kumar, B. (2003) Epidemiology of Skin Diseases in School Children: A Study from Northern India. Pediatric Dermatology, 20, 470-473. https://doi.org/10.1111/j.1525-1470.2003.20602.x 
[20] Faure-Cognet, O., Fricker-Hidalgo, H., Pelloux, H. and Leccia, M.T. (2016) Superficial Fungal Infections in a French Teaching Hospital in Grenoble Area: Retrospective Study on 5470 Samples from 2001 to 2011. Mycopathologia, 181, 59-66. https://doi.org/10.1007/s11046-015-9953-7

[21] Shehu, K., Ashiru, S., Aliero, A.A. and Tafinta, I.Y. (2014) Prevalence of Superficial Mycoses among Pupils in Rural Areas of Zamfara State. Annals of Biological Sciences, 2, 5-9.

[22] Bortolussi, R., Martin, S. and Canadian Paediatric Society and Infectious Diseases and Immunization Committee (2007) Antifungal Agents for Common Outpatient Paediatric Infections. Paediatrics \& Child Health, 12, 875-878.

https://doi.org/10.1093/pch/12.10.875 